\title{
Luis Antón del Olmet y López: un diputado en los estertores de la bohemia
}

\author{
Luis Antón del Olmet y López: \\ a Member of Parliament at the End of Bohemian Age
}

\author{
Virginia Ramírez Martín \\ Archivo del Congreso de los Diputados \\ virginia.ramirez@congreso.es \\ ORCID iD: https://orcid.org/0000-0002-2202-0593
}

\section{RESUMEN}

Luis Antón del Olmet y López (1886-1923) fue un prolífico escritor y periodista con una apasionante y turbulenta vida, gracias en parte a su carácter vivo y pendenciero. Es más desconocida, sin embargo, su faceta política. El presente artículo pretende repasar su actividad como cronista parlamentario y diputado, que lo fue en las legislaturas de 1914-1915 y 1915, para reconstruir esta parte de su biografía que influye significativamente en su ejercicio de la escritura y el periodismo.

Palabras Clave: Luis Antón del Olmet; Congreso de los Diputados; crónica parlamentaria; literatura y política.

\section{ABSTRACT}

Luis Antón del Olmet y López (1886-1923) was a prolific writer and journalist with an interesting and turbulent life, because of his difficult, troublemaker personality. Nevertheless, his political facet is more unkown. This article wants to go over his activity as parliamentary journalist and Member of Parliament during the 1914-1915 and 1915 terms, to piece together this period of his biography that has a meaningful influence on his literary, journalistic works.

Key words: Luis Antón del Olmet; Congreso de los Diputados; Parliamentary journalism; Literature and politics.

\section{INTRODUCCIÓN}

Luis Antón del Olmet y López (1886-1923) es un escritor menor, uno de los tantos que en el arranque del siglo XX aspira a dejar su impronta en la literatura 
española, pero también en la política. Con su muerte se convierte él mismo en carne de la crónica negra, y casi un siglo después en materia literaria cuando Juan Manuel de Prada lo recupera para su galería de personajes con los que recrea la bohemia literaria madrileña de principios del siglo pasado (Prada 2008).

Con una producción literaria nada desdeñable, aunque solo sea por extensa, convendría que se revisase la figura de un autor que tuvo una vida ciertamente interesante y una muerte lo suficiente dramática como para acaparar numerosos titulares en la prensa de la época. Fue casi todo lo que se podía ser en el Madrid de principios del siglo XX: escritor, periodista, bohemio, cronista parlamentario, diputado, dramaturgo, empresario teatral, pendenciero profesional... Tuvo contacto, a veces muy estrecho, con la clase política, con el mundo periodístico, con el sector editorial e, inevitablemente, con el parnaso literario. De esta forma llega a trabar un universo de relaciones, las más de las veces tormentosas, en aquel Madrid de la bohemia que cabalga entre dos siglos y hasta su muerte, que sucedió en 1923.

La última reedición de una de sus obras con mayor predicamento, Historia de asesinos, tahúres, daifas, borrachos, neuróticas y poetas, editada por Rubén López Conde (Antón del Olmet 2012), menciona de pasada que fue diputado, aunque aborda con algo más de profundidad su relación con el partido conservador de Dato y su trayectoria política a las órdenes de José Sánchez Guerra, por aquel entonces Ministro de la Gobernación, y, sobre todo, presta singular atención a su labor de escritor y periodista, al tiempo que traza un perfil pendenciero y canalla, en buena medida a partir de lo que ya otros habían escrito de él. Rafael Cansinos Assens, Rafael Urbina, Emilio Carrere, Nicolás González Ruiz o Federico Sainz de Robles describen al hombre y al escritor; destacan, más allá de sus méritos literarios, que varios ensalzan, una reputación más que dudosa, a medio camino entre el gánster y el vividor, el chantajista y el que alquila su pluma al mejor postor. Este equilibrio entre las diversas pulsiones que latían en el alma de Antón del Olmet queda bien evidenciado en el siguiente fragmento de López Conde:

\begin{abstract}
Estas pocas palabras, sabias, inmediatas, ponderadas, casi premonitorias [haciendo referencia a lo que sobre Antón del Olmet había escrito el crítico Rafael Urbina $]^{1}$, son el mejor y más justo compendio que puede hacerse de la vida y la obra de aquel achulado gigantón, regalado hombre de raza con fama, planta y deje de matón... porque en efecto Luis Antón del Olmet (1886-1923), amén de excelente escritor y periodista, fue un hampón de rompe y rasga, corrupto, pérfido y bronquista, rebajado por la fuerza superior de su genio turbulento (y su particular sentido de la justicia) a personaje central de un folletín de tintes siniestros (Antón del Olmet 2012, [11]).
\end{abstract}

${ }^{1}$ Hace referencia a un pasaje de Urbina en el que dice: «El ingenioso, el fecundo Luis Antón del Olmet ha lanzado una nueva novela [...]. Es un hombre heroico, de temple legendario, que ha nacido para amar y odiar apasionadamente, para arder en la propia hoguera que quema a sus enemigos...» (Urbina 1919, 678-679). 
Rubén López Conde insiste al prologar esta obra en que su intención no es redimir al hombre, aunque muchos de sus pecados podrían ser seguramente perdonados vistos en la perspectiva de una época convulsa, pero sí considera que no es justo el olvido en el que su obra, ingente si se tiene en cuenta que apenas son catorce años de actividad literaria, y sobresaliente por la diversidad de géneros, el dominio de la lengua y la expresividad y viveza de su pluma, ha caído.

Por otra parte, la política fue también una parte sustancial de la trayectoria vital de Luis Antón del Olmet, por lo que este artículo pretende revisar lo que sobre él puede aportar su peculiar paso por el Congreso de los Diputados como cronista parlamentario primero y como diputado después, pero también algunos otros aspectos de su vida, reconstruidos en muchos casos a partir de las pistas que el propio autor va dejando sobre sí en su obra. Porque Antón del Olmet tiene por costumbre dirigirse al lector en muchas de las obras que escribe, unas veces para explicarle el propósito de sus libros y otras para simplemente presentarlos. Puede casi presuponerse sin miedo a errar que este singular personaje demuestra siempre una inagotable benevolencia con respecto a sí mismo, pero entre estas palabras de autoelogio subyacen hechos que otras fuentes pueden venir a constatar.

De lo que otros escribieron de él, como ya se ha recogido, es posible entresacar datos menos elogiosos acerca de su vida y también del juicio que sus contemporáneos tenían de él. A pesar de la reputación que como periodista se labró y de su actividad política, lo cierto es que su carácter contribuyó a rebajar su consideración literaria y también a granjearle numerosas enemistades y pendencias.

Cansinos Assens recuerda a Luis Antón del Olmet en varias ocasiones a lo largo de diversos fragmentos recogidos en La novela de un literato $^{2}$ :

Luis Antón del Olmet, el batallador periodista, ex corresponsal de guerra en Marruecos, autor de novelas estimables y hombre de garra, pícaro de una categoría superior, funda El Parlamentario, periódico subvencionado por los aliados [...] Luis Antón del Olmet es la antítesis de su hermano, el marqués de Dos-Fuentes, el diplomático que naturalmente vive mucho peor que él...

2 Sobre el modo en el que esta obra fue publicada viene muy al caso una Tribuna firmada por Francisco Ayala en El País el 17 de noviembre de 1995. Ayala recuerda que esta es, en realidad, una obra póstuma que ha confeccionado su hijo a partir de diversos papeles que Cansinos Assens dejó, muchas veces reflexiones de diversa índole, redactadas en un «estilo muy libre, desplegado en la intimidad y no constreñido todavía por las consideraciones a que una perspectiva de inmediata publicación acaso obligaran, se logran ahí pequeños relatos de traza magistral, varios de los cuales bien pueden valer como cuentos estupendos, tan pronto divertidos como patéticos. Cuentos, eso sí, cuyos protagonistas son personajes de la vida real, con nombre conocido». No se debe, en mi opinión, perder de vista esta clave dada por Francisco Ayala, pues estas reflexiones tienen con frecuencia mucho de verdad desprovista de artificio literario. 
Antón es el prototipo de novelista venal, que alquila su pluma al mejor postor, cobra del fondo de reptiles, introduce de contrabando mulas en Francia y, sin embargo, presume de quijote, de amparador de humildes, etc., porque sus tiros sólo van contra los ricos (Cansinos Assens 1995, 2: 51-52).

Pinta Cansinos, pues, un retrato mucho más oscuro que claro de este escritor que es aficionado al chantaje, que aprovecha la debilidad de sus protegidos para cometer sus atropellos y, sin embargo, no puede desmentir del todo su calidad literaria y su buen hacer periodístico. Luis Antón del Olmet no parece gozar de su simpatía mientras que es, por otra parte, mucho más comprensivo con el que luego pondrá fin a su vida, Vidal y Planas, por quien siente un cierto afecto.

Parece Luis Antón del Olmet un personaje con más sombras que luces a quien nadie presume intenciones honestas en su proceder y al que pudiera parecer que el destino le deparó justo pago a su conducta. No obstante, interesa aquí repasar sobre todo su vida política para esclarecer aspectos más desconocidos de su biografía que contribuyan a revivir su obra, y que el lector juzgue lo que crea más oportuno.

\section{Algunos Datos Biográficos}

Todas las semblanzas biográficas de Luis Antón del Olmet y López coinciden en constatar que nace en Bilbao en 1886 y muere en Madrid en 1923. También todas dicen que era periodista y escritor. En casi todas las posteriores a 1923 hay asimismo referencias a su muerte, que sucedió en un teatro madrileño y consecuencia de un «incidente» con otro escritor. Y ahí casi acaban las coincidencias, grosso modo.

Antón del Olmet es hijo de Fernando Antón del Olmet Lanuza, funcionario del cuerpo de Aduanas (Ara Torralba 2010, 2) y Casilda López. Tiene dos hermanos, Fernando, mayor que él, y Casilda, que durante su infancia y juventud peregrinan por los diversos lugares de destino de su padre. Su hermano, Fernando Antón del Olmet, marqués de Dos Fuentes, fue diplomático ${ }^{3}$ y también escritor, aunque con menos fortuna, según el juicio de Cansinos Assens, que Luis, pues de él dice:

Como Poeta, el marqués de Dos-Fuentes es una calamidad. [...] Sus versos son ripiosos, duros, ramplones y prosaicos. [...] El marqués de Dos-Fuentes, a pesar de su tradicionalismo, es un hombre tratable y si literariamente es inferior a su segundón, en lo moral es infinitamente superior a ese desenfadado condottiere de la pluma (Cansinos Assens 1995, 2: 67-68).

\footnotetext{
${ }^{3}$ De la carrera diplomática de Fernando Antón del Olmet ofrece cumplidas noticias la Gazeta de Madrid, antecedente del Boletín Oficial del Estado, en la que son publicados sus nombramientos, ceses y ascensos.
} 
Cursó estudios de Derecho en la Universidad Central de Madrid, de ahí que en algunas semblanzas biográficas se diga que fue jurisconsulto (Ramos Roví 2013, 67-70), pero lo cierto es que nunca ejerció como abogado ni se dedicó al derecho. Ingresa como oficial, muy probablemente de cuarta clase, en el Ministerio de Hacienda y obtiene destino en La Coruña (Ara Torralba 2010, 2), aunque ya entonces comienza a desarrollar su carrera periodística.

En el expediente personal que sobre Luis Antón del Olmet se conserva en el Archivo General del actual Ministerio de Hacienda se recogen diversos documentos que completan esta información y desmentirían que su carrera administrativa terminara con su ingreso y excedencia casi inmediata ${ }^{4}$, como afirman las reseñas bibliográficas citadas, sino que esta tuvo un recorrido más dilatado. De su consulta se desprende que, con bastante seguridad, ingresó como oficial de cuarta clase y ascendió a oficial de tercera por elección dada la existencia de una vacante.

En su expediente se encuentra una copia del título de Oficial de Tercera Clase y una minuta relativa al cese en dicho empleo en virtud de su elección como diputado a Cortes durante «todo el tiempo que dure la representación». La fecha del título, como se puede comprobar en la copia literal, es de 10 de septiembre de 1912, y en él se indica que ha sido destinado a servir en la Dirección General de Contribuciones. Por otra parte, se le otorga excedencia con fecha 31 de marzo de 1914 en el puesto que venía ocupando vista su solicitud, en la que expone que ha sido elegido diputado. Esta minuta recoge, asimismo, «que había venido desempeñando, sin interrupción alguna el destino en el que cesa, desde que tomó posesión de él».

En diciembre 1917 se le concede otra excedencia por un año «de conformidad con lo establecido en el artículo 12 del Real Decreto de 16 del actual». Asimismo, en otro documento que se fecha en marzo de 1917, y por lo tanto anterior a la resolución por la que se le declara de nuevo excedente, se recoge que «pase, en concepto de agregado, hasta nueva orden, a prestar sus servicios a esa Subsecretaría», refiriéndose a la del Ministerio de Instrucción Pública y Bellas Artes, procedente de la Dirección General de Contribuciones.

Llama la atención que la carrera administrativa de Antón del Olmet se encuentre documentada entre 1912 y 1917 sin dar lugar a dudas, pues él mismo no cita entre sus ocupaciones la de funcionario, y sin embargo los documentos demuestran que lo fue ininterrumpidamente en estos años y que además se cuidó mucho de solicitar las pertinentes excedencias que garantizaban que conservase la condición de tal en los períodos en los que no era posible per-

\footnotetext{
${ }^{4}$ Así se recoge en el expediente personal de Luis Antón del Olmet López que obra en el Archivo Central del Ministerio de Hacienda (Gobierno de España. Ministerio de Hacienda. Archivo Central [Hacienda], legajo 261, expediente 30.169). Agradezco al personal de este archivo, en especial a Rosa Martín y Julián Arribas, las facilidades para acceder a la documentación a la que hago referencia.
} 
manecer en servicio activo (1914, durante todo el tiempo que durase el mandato representativo como diputado, y 1917 en lo que parece una excedencia por interés particular, aplicando la categoría moderna a la situación). Así, Antón del Olmet habría contado siempre con una fuente, por pequeña que fuera, de ingresos, su sueldo como funcionario, que habría compatibilizado con el desempeño de otras actividades, dado que el ordenamiento jurídico vigente en materia de incompatibilidades era sensiblemente más laxo que el actual.

Más allá de estas cuestiones, sí que parece cierto que en los primeros años del siglo y con motivo de su destino coruñés es cuando Olmet se apega a las tierras gallegas; tanto es así que terminará por llegar a afirmar que es gallego y a aspirar a convertirse, una vez pisa la arena política, en diputado por Padrón. Pronto comenzó a pasear por las redacciones de diversos periódicos, después se convierte en diputado, y acaba fundando su propio periódico, El parlamentario, para terminar escribiendo teatro e, incluso, llevando a las tablas sus obras en colaboración con Alfonso Vidal y Planas, el socio que a tiros puso fin a su vida en el madrileño Teatro Eslava.

Casi todas las referencias biográficas que hacen mención a algo más que estos hechos coinciden también en resaltar su fuerte carácter, un genio vivo que le granjeó numerosas enemistades y no pocas trifulcas a lo largo de toda su vida y que, desde luego, fue uno de los elementos que terminarían por causarle la muerte a manos de Vidal y Planas. Ya desde su juventud se relatan en diversas fuentes encontronazos con otros periodistas, escritores, luego con políticos... En todas las etapas de su vida parece que tuvo desacuerdos dirimidos de mala manera, seguramente como consecuencia de su mal carácter, su bravuconería y esa tendencia natural a la palabra hiriente que tenía.

\section{SU FILIACIÓN POLÍTICA}

Antón del Olmet ingresa en el partido conservador de Eduardo Dato en 1913, con 27 años, y a él se adscribe durante toda su actividad política, primero a las órdenes del ministro Sánchez Guerra como secretario político y como jefe de prensa del Ministerio de la Gobernación, y después accede al acta de diputado dentro del ámbito de influencia de este mismo partido.

Sin embargo, Olmet no tiene impedimento en cambiar de opinión política, a pesar de lo que él mismo afirma, como se verá a continuación, en su obra. Con más realismo describe Pedro Luis de Gálvez el modo en el que mudaba Luis Antón del Olmet de postura política: «Cada vez que "El Parlamentario" corregía su credo político, cambiaba de casa. [...] De casa y de credo, pero nó de política: el ideal de Antón del Olmet, el billete grande» (Gálvez 1926, 1).

Justifica su abandono de las filas de su partido porque, dice, se desencanta de aquel a propósito de la postura del gobierno de Dato con respecto a la 
Asamblea de Parlamentarios que se celebró en Barcelona en $1917^{5}$, si bien sus desacuerdos con el partido tienen mucho que ver con la relación con Sánchez Guerra, como se explicará a continuación. Pero da razón de este desencuentro en una carta abierta a Eduardo Dato que recoge en las primeras páginas de una de sus obras La horrenda politica: los idóneos. Recuerdos de un ex secretario politico. Intimidades del partido conservador:

Ingresé en el partido conservador requerido insistentemente por el Sr. Sánchez Guerra. Aquel día entregué una modesta, pero independiente significación intelectual, poniendo mi corazón y mi pluma al servicio de una causa que me parecía liberal en su especialísima disidencia.

De mi actuación en las filas del partido hablan mis hechos, y usted mismo los pregona. Mi vida, desencauzada por el halago súbito del Sr. Sánchez Guerra, habrá tenido errores involuntarios y hasta inevitables culpas, á las que me vi impelido por el desamparo en que, inmediatamente de captado, se me dejó (Antón del Olmet 1917, 9) ${ }^{6}$.

En La horrenda política: los idóneos Luis Antón del Olmet refiere, pues, los motivos por los que se aparta del partido conservador de Dato, resultando

${ }^{5}$ Reproduce Olmet su apoyo explícito a la iniciativa puesta en marcha por Cambó ante la negativa de Dato a abrir las Cortes en una carta que le remite en la mañana del 19 de julio de 1917 y a la que contesta Cambó. En ella dice: «Lamento no ser ahora diputado. Hubiera asistido a la Asamblea, Creo que les conduce a ustedes un magno sentimiento de Patria, de raza y de energía salvadora» (Antón del Olmet 1917, 7-8). Lo cierto, como se verá a lo largo de las páginas de La horrenda política, es que Olmet se desligó antes de la línea de los idóneos, y que esto no es más que una justificación de su cambio de trayectoria. Una buena síntesis del papel de Sánchez Guerra como ministro de la Gobernación en el momento en el que tienen lugar estos acontecimientos es la hecha por Miguel Ángel Martorell, quien explica que finalmente esta convocatoria se resolvió sin ningún tipo de violencia porque «Fue un pacto entre caballeros, entre iguales; entre viejos amigos habituados a compartir espacios de sociabilidad en el Congreso de los Diputados» (Martorell Linares 2010, 81-84).

${ }^{6}$ Es especialmente reveladora de la intencionalidad de esta obra la primera parte del título, La horrenda política, que deja bien claro el interés de Olmet en retratar las excrecencias del ejercicio del poder y, sobre todo, lo que ello apareja para los ideales. También es importante la fecha de publicación, pues en 1917 Olmet ha dado por concluida su carrera política y es posible entrever, en esta obra, la búsqueda de un ajuste de cuentas con sus antiguos compañeros de bancada. Por otra parte, la mención a los idóneos hace referencia a la escisión que el partido conservador sufrió en 1912 como consecuencia del encargo de formar gobierno que sí aceptó Eduardo Dato y para el que Antonio Maura puso numerosas dificultades, de lo que resulta la división del partido conservador. Así, pues, los conservadores se desgajan entre mauristas y datistas, siendo los primeros minoritarios y más radicales en sus planteamientos, y llamados idóneos los segundos, de talante más abierto y que constituyen la facción mayoritaria. Para un análisis en profundidad de la quiebra en el partido conservador y de cómo afectó a las legislaturas que transcurren entre 1913 y 1917, vid. Martorell Linares 1997. 
este libro una amarga crítica del ejercicio de poder por parte del partido en el que militó, una denuncia del desprestigio de la política de aquellos. Recuerda en el verano de 1917 cómo fueron sus primeros contactos con Sánchez Guerra, la fractura entre mauristas y datistas, la forma en la que fue atraído al partido conservador y su vida durante aquellos años hasta terminar por abandonar el partido.

De su incorporación a las filas conservadoras habla en un tono cargado de rencor; se refiere a ello en el capítulo «Cómo fui captado». Dice que en aquellos días acababa de volver de Marruecos, lugar al que había sido enviado por $A B C$ para que remitiera crónicas de la guerra. En cuanto Sánchez Guerra le pudo localizar en Madrid, le mandó una carta para que acudiera a una cita en el ministerio, momento en el que le ofreció que colaborase con ellos como secretario político, al que asimismo prometió hacer después diputado a Cortes. A un hombre de su juventud entonces, 27 años, le impresiona enormemente el ofrecimiento, según su propio relato (Antón del Olmet 1917, 40-41). Ese mismo día abandona su trabajo en el $A B C$, y Luca de Tena se despide de él con estas palabras:

La política, amigo Antón del Olmet, es una traidora. El paso que da usted hoy le costará caro. Ocupa usted una envidiable posición. No la abandone. Muy pronto se arrepentirá, ya tarde para reparar el daño. Vivirá un ambiente falso, embaucador, que destrozará su bien ganado prestigio (Antón del Olmet 1917, 43).

En seguida el propio Olmet da a entender que la despedida de Luca de Tena fue una profecía muy precisa, pues ya desde que se materializa su renuncia en el diario es tratado con indiferencia por el ministro. Poco después llega a ocupar la Jefatura de Prensa, un cargo que describe de forma muy negativa, tildándolo de «retiro para gacetilleros veteranos, pero nada envidiable para la sangre caliente de un mozo». A través de las páginas que siguen se despacha con el cargo que ejerció y más aún con su jefe, el ministro Sánchez Guerra, pero también con algunos otros personajes con los que convivió entonces. El capítulo XI, que lleva por título «Seré un diputado cunero», refleja la concepción que de la realidad política gallega tiene Antón del Olmet y aquí se alude a su elección de Padrón como distrito electoral, cosa que finalmente, como también se aclara en el libro, no llegó a materializarse.

Algún capítulo después menciona el librito verde en el que Sánchez Guerra anotaba los nombres de los futuros diputados, candidatos en las elecciones más bien, y los nombres de los distritos electorales. Relata Antón del Olmet cómo era el procedimiento de elección de las candidaturas que él tuvo ocasión de presenciar. Tras criticar muy amargamente el mecanismo al que recurría Sánchez Guerra acaba por reconocer, sin embargo, que realmente eran cada vez más los distritos en los que el ministro carecía de influencia para colocar a sus candidatos (Antón del Olmet 1917, 114). Dedica aún algún pasaje más del libro 
a ahondar en cuestiones electorales, recurriendo al símil de la política vieja para subrayar, de paso, que a pesar de la relativa efectividad de los métodos de Sánchez Guerra estos están cada vez más próximos a la extinción. Finalmente se ocupa de su elección como diputado a Cortes por Almería.

Por sus páginas desfilan diputados y miembros del Gobierno, y pocos superan indemnes el juicio a que los somete Luis Antón del Olmet. Este libro sirve de redención al periodista que abandonó su carrera por la política y que, para poder volver a ella de forma honorable, redacta este pliego de descargo que puede resumirse en unas pocas líneas:

Ellos me desencauzaron de mi ruta. Ellos me abandonaron. Ellos me corrompieron. Volved á Dato y á Sánchez Guerra los ojos cuando queráis acusarme. Ved en mí al de ayer y al de hoy, no al de la captación idónea. [...] Me hubiera sido fácil conservar mi puesto y hacer una brillante carrera. Lo difícil es llegar y yo habría llegado. [...] Yo salí del idoneísmo y de la pocilga en un impulso propio de inadaptable. He tirado una subsecretaría. He tirado una fortuna. [...] Creo ahora que se puede hacer un diario independiente y honorable. Me anima una legítima esperanza. Pero si ello no fuera posible, reduciría mi vida á lo mínimo, y si fuera necesario pasar grandes privaciones para guardar el honor, sabría hacerlo (Antón del Olmet 1917, 381-382).

\section{Olmet Periodista}

Luis Antón del Olmet es periodista, un periodista que también escribe literatura y que tiene un intenso romance con la política, pero que acaba siempre por volver a las rotativas. Durante toda su trayectoria aquella ocupación a la que dedica más tiempo es al periodismo. Olmet está vinculado a la prensa a lo largo de prácticamente toda su vida, incluso en muchas de sus obras literarias late el pulso del periodista, y así se presenta el propio Luis Antón del Olmet al lector de El libro de la vida bohemia:

No soy literato, no pienso serlo, ¡voto á Cristo! Te juro á Dios que antes de oírme llamar de esa manera, subiría á la horca. Que tal como se han puesto los tiempos, definirse á sí mismo literato, equivale á sumarse, á confundirse. Yo aspiro un poco á ser original. Yo no soy literato. Así, entre un pueblo formado por gentes literarias, tendré mi sello personal, no codiciando semejante apodo, y seré un hombre inusitado y casi extravagante. Soy periodista. No encuentro otra palabra. Escribo, pero escribo ligero, al azar, á la buena de Dios, mientras ruge la máquina en la imprenta y el regente alarga hacia la mesa de redacción su mano ávida. Esto quiere decir que soy inconstante, que me apasiono súbito, que me olvido pronto, que soy vario, tornadizo, voluble (Antón del Olmet 1909, 7-8).

En la semblanza que se hace de él en Las Cortes Españolas: las de 1914 (Sánchez y Redondela 1914), habiendo accedido ya a la condición de diputado, se destaca su actividad como periodista, y es que esta fue la que le reportó 
mayor celebridad. Se dice que al inicio de ésta fue redactor de $\mathrm{La}$ Época, El $M u n d o$, Noroeste, y algo después director de El Debate, redactor de $A B C$ y en el momento en el que se redacta la obra director de El Parlamentario, periódico del que fue también su fundador, si bien este dato no figura en esta nota biográfica. En estas líneas se indica que «a fuerza de talento y corazón» muy pronto se convirtió en primera figura de la prensa española. En un tono marcadamente laudatorio, se describe su carácter y también su estilo literario al tiempo que de sus obras se dice que:

Son sencillamente imponderables, por el arte de decir, por la sensación de realidad que transmiten, por el deleite que producen, por el garbo y la nobleza con que, en definitiva, hasta cuando se entrega al adjetivo injusto o cuando arremete contra aspas de molino, desface entuertos y persigue ideales (Sánchez y Redondela $1914,588)^{7}$.

En la presentación de otra de sus obras, Maura es obra mía (España en pie), presentación a la que el autor llama «Estudio introductorio», glosa así la celebridad que como periodista alcanzó:

Por los años de 1912, de 1913, yo era un ídolo en España. Mi hermano, al regresar de Constantinopla, en cuya legación servía, quedó absorto ${ }^{8}$. No se hablaba sino de Antón del Olmet. Cuando daba su apellido le decían: «¿Es usted el gran periodista?». Como evoco una cosa pasada, no he de vestirme con galas que ya no me pertenecen [...] Iba para ministro y me quedé en escritor humilde. No se vea en estas confesiones vanidad [...]. Yo fui, repito, por los años 12 y 13 el periodista más leído y mejor comentado de España. Tuve por tribuna el periódico $\mathrm{ABC}$, que entonces era el periódico único (hoy ha perdido buena parte de su prestigio espiritual) [...]. Si alguien ha conocido la popularidad, fui yo. No podía ir á ciudad, villa ó aldea donde no se me elogiase. En la calle, en el tranvía, me detenían personas desconocidas para felicitarme (Antón del Olmet 1919, 10-16).

De su época en Marruecos publica después Marruecos (de Melilla a Tánger), libro que recoge buena parte de las crónicas que publicó en El Debate y $A B C$. También ilustra esta obra un pequeño prólogo en el que el autor recuerda sus días en Andalucía y Marruecos y unas líneas al final, «Para acabar», que sirven para recapitular sus conclusiones sobre aquellos años y esos acontecimientos (Antón del Olmet 1916).

${ }^{7}$ Es bien cierto que este tipo de obras suelen tener un carácter ciertamente benéfico con los reseñados. Por otra parte, estas obras, las que recogen semblanzas biográficas de los nuevos diputados al comienzo de cada legislatura, son muy habituales en la primera mitad del siglo XX y, en algún momento, pasan a ser editadas por las Cortes, desde que los propios diputados facilitan sus datos biográficos más reseñables.

${ }^{8}$ Se refiere a Fernando Antón del Olmet, a quien ya se ha hecho referencia, diplomático y también escritor. 
Fruto de su actividad periodística es también la recopilación de artículos en la obra La vampira de la calle de Poniente: crónica de un suceso, que también ha sido recientemente reeditada por Ginger Ape Books \& Films (Antón del Olmet 2013). Este libro cuenta uno de los sucesos más escabrosos narrados por la prensa de aquel entonces (1912-1913), la historia de Enriqueta Martí, aderezada con datos no siempre verídicos pero sí destinados a atrapar a los lectores en una crónica de lo más truculenta que se abre con el hallazgo de una niña cuya desaparición había sembrado Barcelona de temor y que destapa una serie de secuestros relacionados con la corrupción de niños y otros asuntos igualmente tétricos.

Funda después Luis Antón del Olmet el periódico El Parlamentario ${ }^{9}$, cuya dirección ocupa hasta el 2 de noviembre de 1918, según se indica en el prólogo de la edición de Gobernación, Sánchez Mínguez: novela ${ }^{10}$ cuando se transcribe el discurso que en su honor se pronunció en el banquete de despedida que los miembros de la redacción dieron en su honor con motivo del abandono de este cargo. Se dice en diversos lugares, y él mismo lo reconoce así en la novela Los idóneos, que este periódico funcionó como órgano de difusión de los partidarios de Dato y que, por lo tanto, el periodista servía a los intereses del partido, de manera que su periodismo no era tan libre como él se jactaba. Las oficinas del mismo estaban primero en la misma Carrera de San Jerónimo, y después en el número 12 de la calle Santa Catalina.

\section{OlMET CRONISTA PARLAMENTARIO}

Antes de llegar a fundar y dirigir su propio periódico, la carrera periodística de Antón del Olmet fue fecunda y diversa. Olmet prefería, de entre todas sus dedicaciones, la periodística, y de ello deja constancia en diversas ocasiones. Sin embargo, de su labor como periodista, muy dilatada y en muy diferentes periódicos, destaca de manera muy significativa la serie de crónicas parlamentarias que hace que deba ser, en justicia, considerado un cronista parlamentario como otros que son de sobra conocidos, como Azorín, Fernández Florez y algunos más, si bien Ara Torralba sitúa sus crónicas

${ }_{9}$ Del funcionamiento de este periódico hay diversas noticias en la obra de Cansinos y del propio Olmet, pero Gálvez, que trabajó allí primero como redactor y después como redactor-jefe, alude también a ello en este fragmento: «El periódico se vendía poco; la caja, exhausta, dos acreedores, con el mal de San Vito; el personal cobraba irregularmente; que era lo regular, si cobraba» (Gálvez 1926, 1).

${ }^{10}$ Así se recoge como inicio de esta obra, tras la reproducción del discurso pronunciado por Ángel Samblancat, que tuvo lugar en el banquete celebrado ese día por la redacción de El Parlamentario con motivo de la marcha de Antón del Olmet de la dirección del periódico. Vid. Antón de Olmet 1921. 
dentro de la contribución editorial del «periodista amarillo» (Ara Torralba $2010,4)^{11}$.

La dedicación a la crónica parlamentaria está recogida no solo en los diarios en los que trabajó Antón del Olmet, sino que se compila en dos obras de cierta importancia de las que desgraciadamente no se han podido recabar datos acerca de su difusión ${ }^{12}$. Se trata de Su señoría. Libro parlamentario y Política de fandango y gobierno de castañuelas.

Dice el mismo Olmet que alguien tuvo la ocurrencia de solicitar su pluma para la crítica parlamentaria. Y añade, para explicar lo poco que inicialmente le apasiona esta nueva dedicación con respecto a su trayectoria previa como periodista y escritor:

Acudí sin agrado, sin fruición, con ese gesto melancólico que adoptamos al vestirnos un traje mal zurcido y al ponernos cerca de una novia no querida. El cronista de tabernas y salones, de gentileza y bellaquerías, que ha metido su pluma en la sangre del arroyo, en la grata, voluble ambrosía del epitalamio, que se ha paseado por la vida literaria sin hacer remilgos, con una princesa y una meretriz trincadas en los brazos, que ha buscado motivo de inspiración dondequiera que un corazón palpitase, fue sin ilusión, de mal grado, al Parlamento (Antón del Olmet 1911, 7-8).

El primero de estos dos libros, Su señoría, a caballo entre la descripción y la opinión, dedica las primeras páginas a lo que el autor llama «Decoraciones» y en las que pretende trasladar al lector al escenario del Congreso, dibujándoles sus salas en una prosa trufada de anécdotas. Presta singular atención a la biblioteca, que describe como «un remanso de cultura entre las aguas violentas de un rumoroso río». La siguiente sección, «Hombres», recoge las particulares semblanzas que de los principales diputados hace Olmet y con los que se muestra satírico, ácido, a veces hiriente; pocos escapan al duro juicio del cro-

${ }^{11}$ El autor no solo circunscribe al amarillismo estas dos obras, sino algunas más, que él mismo indica que no es una relación exhaustiva de todas las que se ajustarían al género, «para no cansar al lector».

${ }^{12} \mathrm{La}$ única referencia que se ha podido recopilar a este respecto tiene que ver con la adquisición de 500 ejemplares de la obra Su señoría con destino a las Bibliotecas públicas del Estado (Gaceta de Madrid núm. 117, 27 de abril de 1913, pp. 294-295). En la Gaceta se recoge que esta adquisición, cuyo importe total es de 1.500 pesetas, se hace previo informe favorable de la Junta Facultativa de Archivos, Bibliotecas y Museos y la Real Academia de Ciencias Morales y Políticas. En el segundo de estos informes, el de la Real Academia, se indica que la Junta Facultativa ha considerado la obra «no sólo de utilidad, sino de necesidad en la Bibliotecas públicas». Asimismo la Real Academia considera que «es bien difícil que pudieran aspirar obras formadas del modo que se ha formado la que actualmente se examina (una colección de artículos) á que se declararan de mérito relevante, $[\ldots]$ aunque pudiera en esta ocasión reconocerse ese mérito relevante en el estilo literario, que siempre es original porque siempre es personalísimo, y que en los artículos de «Su señoría» resplandece con caracteres de indudable novedad». 
nista. «Muchedumbre», «Momentos», «Debates célebres»y «Los que no son diputados» completan la parte de la obra que dedica al Congreso.

A pesar del disgusto que dice experimentar al comenzar su etapa de cronista parlamentario y del que habla en las primeras páginas, acaba el autor reconociendo en otro pasaje, «La tribuna de la prensa», la ilusión que experimenta al entrar allí, algunas curiosidades del pase rojo, la relación con los ujieres, para acabar por reconocer: «Soy feliz». Es, pues, esta obra, como muchas de Olmet y como casi parece su propia vida, una serie de contradicciones que enfrentan la imagen de periodista impenitente con el que se encuentra en su casa al cubrir la información parlamentaria; la del que critica sin medida a los diputados para terminar alabando su función.

La segunda parte del paseo, como el mismo autor dice, le lleva al Senado, comenzando así: «El Senado, sestea». Articula su descripción de lo que allí sucede en torno al tópico que ha escogido para presentarlo, banalizando la discusión del proyecto de ley que se aborda, caricaturizando las intervenciones y trivializando la votación; y concluye de forma lapidaria:

El espectáculo no ha podido ser más bello, más prestigioso. A la nación, sólo por el capricho de ver reunidos á tantos viejos, ilustres hombres, le ha costado algunos miles, bastante miles de pesetas. [...] El Senado políticamente, es un absurdo, y económicamente es un despilfarro. Es una cosa llamada á fenecer. Agoniza... (Antón del Olmet 1911, 202).

La última parte del libro, «Aventuras del león español» (Antón del Olmet 1911, 205-215), se inaugura con la descripción del diputado ideal; uno llegado de provincias y harto de ver el tedioso y cruel espectáculo dado por quienes están destruyendo la patria, que llega a la capital dispuesto a acceder a un escaño. Logra su propósito, y sin embargo, de nada sirve, pues nadie hace caso a lo que dice, le tratan como un loco, se ríen de él, ahogan sus palabras con sus voces y sus chanzas; y se marcha con las crónicas de los diarios burlándose de su intervención, y eso que llegaba cargado de grandes ideas y proyectos con los que solucionar todos los problemas de España.

Concluye la obra con un final optimista, así se llama el último de los capítulos, pues acaba por explicar su autor que lo que pudiera parecer una crítica demoledora y exclusivamente negativa, es en cierto modo una reivindicación de lo bueno que hay allí, que desgranar lo malo debiera servir para hacer brillar lo bueno, pues acaba por reconocer que son más los buenos diputados que los malos, y que la labor que allí desempeñan no carece de importancia en absoluto. Es este, pues, otro de los contrasentidos, de las incoherencias propias de Luis Antón del Olmet quien, sin profundizar en los debates ni ofrecer más argumentos, desliza opiniones, a veces tremendamente peyorativas, sobre aquello que ve, sin ahondar en las razones; describe implacable la inutilidad de lo que presencia para luego alabarlo. 
Política de fandango y gobierno de castañuelas (Antón del Olmet 1914) el otro de sus libros dedicado al Congreso de los Diputados, es un libro de impresiones de un cronista parlamentario que describe de forma preclara lo que sucede en el salón de sesiones del Congreso como el «gran espectáculo español» (Antón del Olmet 1914, [17]).

Esta idea, la del parlamento como espectáculo, sirve de hilo conductor de estas dos obras. En Su señoría llega a describirlo como «un espectáculo admirable», y añade que «es por lo menos, el primero de los teatros españoles» (Antón del Olmet 1911,9), donde se representa una comedia monstruosa e inverosímil, una farsa colosal en la que participan todos los españoles. Abre este mismo libro con una curiosa sentencia: «El Congreso. Helo aquí. Cervantes, con su eterna mirada broncínea, lo avizora desde su pedestal. Tiene una fachada griega, y unos leones íberos. Dentro, la comedia nacional, palpita. ¡A ver, paso a España!».

Esta consideración, la del parlamento como espectáculo e, incluso, comedia, que puede parecer negativa, vista en el contexto de este prólogo que lleva por título «Palabras cínicas» es, sin embargo, una opinión matizada después por el conocimiento, por lo que de bueno el autor ha podido entrever apartando los prejuicios y desvistiendo de farsa eso que allí sucede. También considera que hay una parte de culpa en el cronista, pues «en general ha tenido muy malos cronistas el Parlamento» (Antón del Olmet 1911, 8), periodistas prejuiciosos e interesados que han ofrecido crónicas interesadas también, movidas por el interés particular de sus autores y no por la necesidad de ofrecer información e impresiones veraces de lo que allí estaba sucediendo.

Este libro, Política de fandango y gobierno de castañuelas, recoge las crónicas relativas al gobierno de Canalejas (1910-1912) y los dos gobiernos de Romanones ${ }^{13}$. Así justifica el autor la edición de esta obra:

He venido escribiendo durante algunos años mis impresiones parlamentarias. Como las escribí con el corazón, sin otra finalidad que hacer patria, gustaron entre la gente sana y buena. Alguien me ha insinuado que las recoja en un libro. ¡Bien!... ¡Allá van!... Son un trozo documentado y sincero de la política española. Si alguna vez, pasado mucho tiempo, cierto curioso investigador de lo inaudito, quiere saber cómo gobernaron los hombres liberales á comienzos del siglo XX, leerá estos rasgos y dirá tal vez: «No tenía gran talento el autor, pero escribía honradamente». Esta ilusioncilla me decide á imprimir la obra actual. Lo demás, me tiene sin cuidado (Antón del Olmet 1914, [13]).

${ }^{13}$ Los dos volúmenes que conforman esta obra se distribuyen como sigue: el primero está dedicado al Gobierno de Canalejas y subdividido en una primera y segunda etapa; el segundo abarca lo que su autor ha identificado como tercera etapa del Gobierno de Canalejas y las otras tres etapas que conforman el Gobierno de Romanones. De la breve interinidad de García Prieto como consecuencia del asesinato de Canalejas no tiene crónicas, si bien sí que inaugura las dedicadas a Romanones con una breve descripción de los hechos. 
En él Antón del Olmet refiere las sesiones vividas, el ambiente que rodea a cada una de ellas, los debates, las intervenciones de los oradores y la expectación de las tribunas. Es una obra curiosa ya desde su dedicatoria: «A los maceros parlamentarios que oyeron tantos discursos, en prueba de misericordia».

A lo largo de sus breves capítulos, dedicados por lo general a narrar lo acontecido en una sesión o algún acontecimiento a propósito de la vida parlamentaria, el cronista Antón del Olmet refiere sus opiniones, desgrana sus afectos y desafectos, narra, en resumen, lo que sucede en el parlamento español desde la perspectiva de quien es parte del «monstruo de cien plumas» (Antón del Olmet 1914, [285]) que son los periodistas que acuden a dar puntual información de lo que en el Palacio de las Cortes sucede.

Esta obra ofrece también peculiares detalles de la vida parlamentaria al describir los trajes de los maceros, el sonido de los timbres que avisan a sus señorías del comienzo de la sesión, o al pararse a detallar cómo ha sido el cambio de la tapicería de los escaños (Antón del Olmet 1914, 17-20).

La asistencia de Olmet a las sesiones fluctúa a veces entre el hastío, la indignación, el interés, de nuevo el aburrimiento ${ }^{14} \ldots$ Se muestra especialmente crítico con el discurrir de las sesiones al inicio de la crónica que lleva por título «La feria de los apetitos»:

El espectáculo parlamentario envenena. Cuando se asiste durante ocho días, quince días, durante un mes ó durante un año al Congreso, llega un instante en el que nos hemos ido saturando por aquel vaho consternador y en el que nada nos sorprende. Parece como si fumásemos opio (Antón del Olmet 1914, [650-651]).

Poco después de plasmar estas descripciones de la vida parlamentaria, O1met da el salto de la tribuna de la prensa al escaño, convirtiéndose en diputado.

\section{El Diputado Olmet}

Luis Antón del Olmet resulta elegido diputado por Almería en las elecciones que se celebran el 8 de marzo de $1914^{15}$, si bien, fruto de aquella elección permanece en la cámara en dos legislaturas, las de 1914-1915 y 1915, en las

${ }^{14}$ El autor señala no pocas veces que el ritmo de las sesiones es casi siempre el mismo, llegando a decir en alusión al orden de ese día: «El programa de todos los días, como la carta de los hostales baratos. Unos discursos leves á primera hora. Después, las ya terribles carreteras. Luego, los manidos presupuestos. Al final, contumaz, depravada, la sesión secreta. Y nada más» (Antón del Olmet 1914, [228]).

${ }_{15}$ En algunas biografías relativas a Antón del Olmet se indica que fue diputado por Padrón (vid. Hernández Cano 2010, 477). Lo cierto es que la revisión de su credencial no deja lugar a dudas: fue diputado electo por Almería. 


\section{Elecciones de Diputados á Codtes}

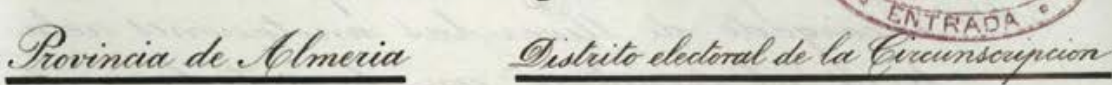

Creadrcial de Qivutado á Cortes electo á aver ac Don Luis de Anton delOlmet y Lopez

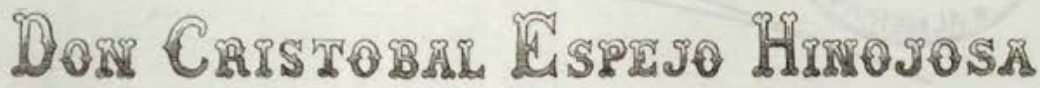 Secretaxio de la Iunta 9rovincial del Censo Electoral}

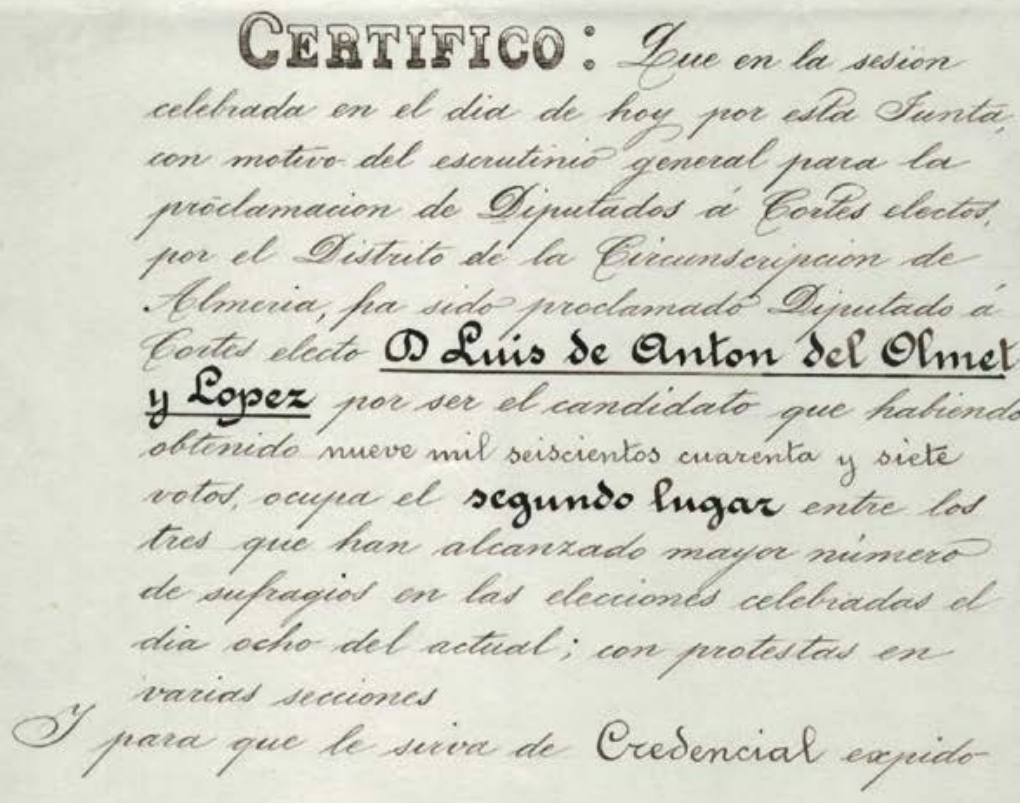

Figura 1. Credencial de Luis Antón del Olmet y López

Fuente: ACD, Documentación Electoral, legajo 125, núm. 4. 
que apenas hay actividad durante dos meses, causando baja como diputado el 16 de marzo de 1916, fecha de la convocatoria de nuevas elecciones.

Las dos legislaturas en las que resulta diputado han de ser examinadas en el contexto de una profunda crisis parlamentaria que se extiende desde 1913 hasta 1917, en la que se fractura irremisiblemente el sistema del turno y, fruto de aquello, se alteran las relaciones parlamentarias que se habían venido manteniendo desde la Restauración. Esta quiebra sistémica se traduce en una acentuada inestabilidad de los gabinetes de Dato, Romanones y García Prieto que, como bien afirma Miguel Ángel Martorell, «apenas pudieron legislar y apuraron los límites constitucionales para tener cerradas las Cortes» (Martorell 2010, 81). Son, pues, las Cortes de las legislaturas citadas en cierto sentido inoperantes, limitadas, y bloqueadas de una parte por la parálisis de los diezmados partidos del turno y las arremetidas obstruccionistas de los partidos minoritarios.

No es tampoco Olmet un diputado brillante ni con una gran iniciativa, como se verá a continuación. Apenas forma parte de algunas comisiones especiales que tratan asuntos menores y tampoco le asiste una posición de fuerza dentro de su partido.

El propio Olmet en Los idóneos ofrece noticias de su paso por el Congreso de los Diputados tras la consecución del acta. Dice de sí mismo que es un «diputado cunero», pues accede al acta de diputado por Almería, circunscripción a la que no le une ningún tipo de vínculo, y no por alguno de los distritos de Galicia, como él mismo dice que era su deseo.

Antón del Olmet tiene una participación más activa en la primera de las dos legislaturas en las que es diputado, siendo en la primera elegido para formar parte de la Comisión de Corrección de estilo, seguramente en atención a su actividad literaria, y de la Comisión para presentar a Su Majestad el Mensaje de Contestación al discurso de la Corona. Asimismo participa en diversas comisiones especiales, como son la del Ferrocarril secundario de Aznalcóllar a la estación de Cuchichón, la de las Fuerzas permanentes del Ejército para 1914, la que se constituye para dar fuerza de ley a un Real Decreto relativo a la plantilla de oficiales de Administración del Ministerio de Fomento, otra para la modificación del párrafo primero del artículo 303 de la Ley de Enjuiciamiento militar de Marina, otra incluyendo entre los embarcaderos económicos generales que deben construirse en las Islas Canarias uno en la ensenada del Médano y otra más para la reorganización del Cuerpo General de la Administración de la Hacienda Pública ${ }^{16}$.

${ }^{16}$ En virtud del Reglamento vigente para el funcionamiento del Congreso de los Diputados en esa legislatura, aprobado el 4 de mayo de 1847 y modificado en diversas ocasiones $(1864,1878,1880,1883,1887,1894,1895$ y 1896), todas las comisiones creadas por el Congreso tendrían "carácter especial para un objeto determinado", excepción hecha de las Comisiones de Actas electorales, Incompatibilidades, Presupuestos, Examen de cuentas, Concesión de gracias y pensiones a persona o personas determinadas, Peticiones, Gobierno Interior y Corrección de Estilo, según se dispone en los artículos 70 y 71. 
De su actividad en la mayor parte de estas comisiones ofrece noticias el Diario de Sesiones, donde se registran sus intervenciones. De su elección para integrar la Comisión de Corrección de Estilo, por el contrario, no hay ningún registro más allá de su designación inicial para formar parte de esta comisión. Así se recoge en el Diario de Sesiones del 30 de abril de $1914^{17}$, sin embargo, y como detalla el reglamento vigente en aquel momento ${ }^{18}$, cada una de las secciones designaba un individuo para formar parte de esta comisión, y entre ellos se escogía a los dos que finalmente serían miembros de ella junto a uno de los Secretarios, que era a su vez designado por la Mesa. En esta legislatura acabaron por constituir la Comisión Permanente de Corrección de Estilo, además del Secretario Primero, el Sr. Conde de Peña Ramiro, los diputados Manuel Bueno Bengoechea y Alfredo Vicenti Rey, ambos también escritores y periodistas ${ }^{19}$.

De su participación en la Comisión designada para presentar a S. M. El Rey el Mensaje de Contestación al discurso de la Corona y de todos los aspectos relativos a la organización de la entrega en el Palacio Real de este mensaje se puede recabar información en otro expediente que custodia también el Archivo del Congreso de los Diputados ${ }^{20}$. El mensaje, por su parte, fue objeto de publicación en el Diario de Sesiones.

Asimismo en la sesión de la Comisión de Gobierno Interior que se celebra el 20 de junio de 1914 se trata, entre otras cuestiones, la concesión de diversas subvenciones para la edición de obras; en esta sesión se adopta el acuerdo de adjudicación, previo informe de la Subcomisión de Biblioteca, para «ayuda de los gastos de edición de algunas obras». Entre la nómina de obras y autores figura Luis Antón del Olmet, a quien se concede una subvención de quinientas pesetas para la edición de la obra Alfonso XIII'1.

17 DSC-C. n. ${ }^{\circ}$ 17, 30 de abril de 1914, páginas 424-425. Se indican ahí los otros diputados que han sido seleccionados para integrar la citada comisión, y que son los señores Argente, Canals, Bueno, Martínez Ruíz, Vicenti (d. Alfredo), Antón del Olmet y Moya y Ojanguren.

${ }_{18}$ Reglamento del Congreso de los Diputados de 4 de mayo de 1847, artículo 76.

19 Archivo del Congreso de los Diputados (en adelante ACD), Serie General, legajo 421, núm. 7: Designación de la Comisión de Corrección de Estilo para la legislatura de 1914.

${ }^{20}$ ACD, Gobierno Interior, legajo 85, núm. 104: Mensaje de Contestación al discurso de la Corona en junio de 1914. En este expediente se indica que el 22 de junio de 1914, a las 12 horas, los miembros de esta comisión fueron recibidos por Su Majestad el Rey. Además del documento en el que figuran los diputados escogidos para integrar esta comisión, se recoge otro en el que se indica sólo el nombre de los que han aceptado su designación, y entre estos se encuentra Luis Antón del Olmet. Asimismo se hace constar que «se ha servido ordenar que a las diez y media de mañana lunes vayan seis coches de cuatro asientos a recoger en sus domicilios para trasladarlos al Congreso, donde deberán encontrarse antes de las once y media a los diputados que a continuación se expresan». El primero de los diputados de esta nómina es D. Luis Antón del Olmet, que será recogido en la calle Lista número 66.

${ }^{21}$ ACD, Gobierno Interior, Actas, Sesión de la Comisión de Gobierno Interior de 20 de junio de 1914. 
La firma manuscrita del autor se conserva en otro de los expedientes que custodia el Archivo del Congreso de los Diputados y que se corresponde con una Proposición de Ley modificando el párrafo 2 del artículo 5 de la Ley de Vigilancia y Seguridad de 27 de febrero de $1908^{22}$. Esta proposición, presentada en febrero de 1915 fue, sin embargo, retirada por su autor pocos días después, el 29 de febrero durante el desarrollo de la sesión, tal y como figura en el extracto del Diario de Sesiones que acompaña también el expediente relativo a esta proposición con objeto, según expone el propio diputado, de que sea distribuida a las secciones para autorizar su lectura ${ }^{23}$.

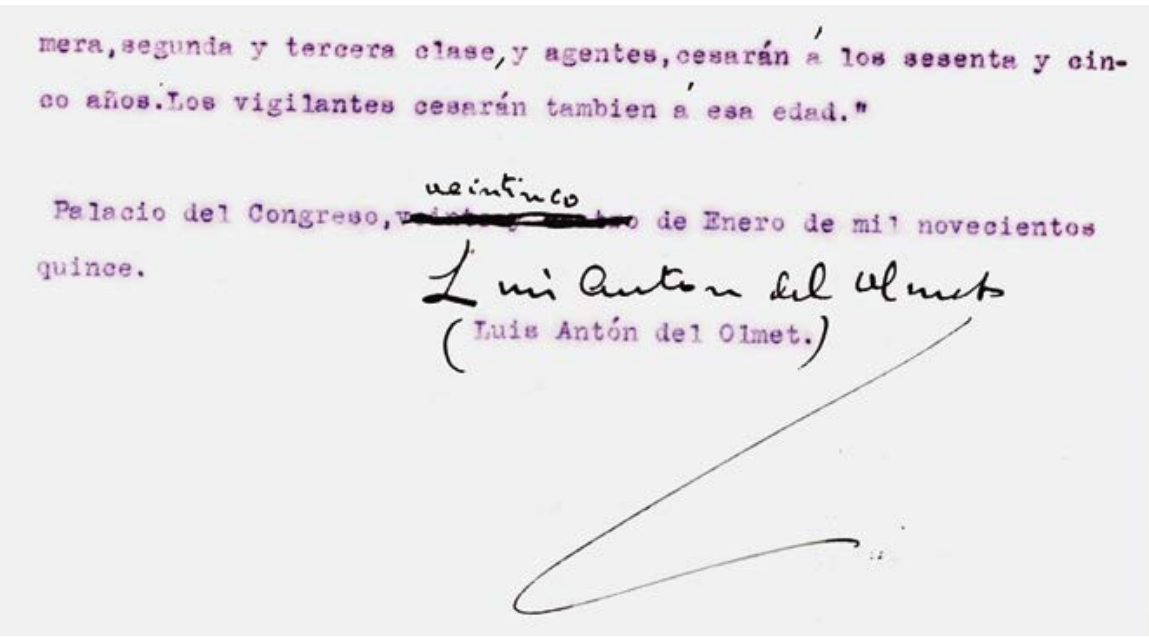

Figura 2. Firma manuscrita de Luis Antón del Olmet

Fuente: ACD, Serie General, legajo 421, núm. 8.

En la segunda de sus legislaturas participa solo en una comisión, la que se constituye para el estudio de la provisión de vacantes y jubilaciones en el Cuerpo de Policía. También Olmet relata en Los idóneos su posición «pro policía», explicando que hizo ella su bandera, pues «amo á los policías como

${ }^{22}$ ACD, Serie General, legajo 421, núm. 81: Proposición de ley modificando el párrafo 2 del artículo 5 de la Ley de Vigilancia y Seguridad de 27 de febrero de 1908.

${ }^{23}$ De la diversa historia que sobre los mismos hechos narra Olmet en Los idóneos conviene traer a colación las líneas que dedica a esta proposición retirada en realidad pero a la que él atribuye otra causa: «De aquella proposición mía [aludiendo a esta misma], que el Sr. Quejano y Toro fue demorando sagazmente para que no saliera á flote, ya sólo queda un vago recuerdo» (Antón del Olmet 1914, 305). 
hermanos. Ellos [...] me han hecho sentir por vez primera la pequeña gloria de ser diputado» (Antón del Olmet 1914, 318). Presenta el diputado, con las firmas de Eduardo Barriobero, José Francos Rodríguez, Antonio Rodríguez Lázaro, el Vizconde de Amaya y Jacinto Felipe Picón, una proposición de ley modificando dos artículos de la Ley de 27 de febrero de 1908 con objeto de que diversas escalas policiales tengan derecho a jubilación tras su cese a los sesenta años de edad ${ }^{24}$. Este texto es realmente casi idéntico al que retiró en febrero del mismo año, si bien incorpora otra modificación relativa a la promoción profesional que supone la modificación del artículo 4 de la citada ley.

De esta época procede una intervención curiosa en el salón de sesiones, un ruego de carácter literario, como él mismo lo describe, que dirige al Ministro de Instrucción Pública ${ }^{25}$. Persigue Olmet que se conceda algún tipo de concesión económica al poeta Amado Nervo, residente entonces en España como miembro de la legación diplomática de su país, que se encuentra en una precaria situación económica como consecuencia de la inestabilidad que el servicio diplomático sufre por los cambios de gobierno propiciados por la revolución ${ }^{26}$.

La exposición del citado ruego tiene, en efecto, un contenido literario innegable; tanto es así, que Antón llega incluso, tal y como refleja el Diario de Sesiones de la fecha, a declamar en el hemiciclo un poema de Nervo, que le sirve para remarcar los lazos que al poeta mejicano le unen con España:

Señor, Rey de una tierra de clásica hidalguía

En donde, en otros tiempos, el sol no se ponía;

Rey de esta madre patria que miran como hijos

Innumerables pueblos, los cuales tienen fijos

Hoy en ella sus ojos oscuros, con amor;

Descendiente de claros Monarcas, oh Señor,

En vos miramos todos los hijos de la grey

Hispana al joven símbolo de la raza. Sois Rey

Aún, en cierto modo, de América, como antes;

Rey, mientras que el idioma divino de Cervantes

Melifique los labios y cante las canciones

De diez y ocho Repúblicas y cincuenta millones

De seres; mientras rija las almas y la mano

El ideal austero del honor castellano.

Rey, mientras que las vírgenes de esa América mía

Lleven en sus miradas el sol de Andalucía;

Rey, mientras que una boca, con celeste reclamo,

Pronuncie en nuestra lengua sin par un "Yo te amo»

${ }^{24}$ DSC-C n. ${ }^{\circ} 5$ de 10 de noviembre de 1915 , apéndice $4^{\circ}$.

${ }^{25}$ DSC-C n. ${ }^{\circ} 19,26$ de noviembre de 1915, 467-468.

${ }^{26}$ En los días en los que Antón del Olmet formula su ruego el poeta Amado Nervo reside en España. Lo hizo entre 1905 y 1918, donde ejerció como diplomático y en este intervalo establece diversas relaciones personales, políticas y literarias. Para conocer más en detalle la etapa de Amado Nervo en Madrid, vid. Simón Díaz (1993). 
Este ruego se ve completado, como fue el consejo del señor Ministro, con la presentación de una proposición de ley por parte del diputado concediendo una pensión de 7.500 pesetas anuales al poeta mejicano Amado $\mathrm{Nervo}^{27}$.

En una sola página manuscrita y autógrafa, Antón del Olmet presenta una proposición de un único artículo que dice «En atención a sus merecimientos literarios, tan ligados a la Patria Española, y para sintetizar con ello el amor que España siente por sus hermanos de raza, los hispanoamericanos, se concede al poeta mejicano, D. Amado Nervo, mientras duren las amargas circunstancias por las que su país atraviesa y que le tienen privado de su sueldo como secretario de Legación, la pensión de 7.500 pesetas anuales». Se fecha en el Palacio del Congreso el 26 de noviembre de 1914. A pesar de que figura la anotación «A las secciones para autorizar la lectura», parece que el fin de la legislatura hizo que esta proposición de ley no continuara su tramitación y, dado que Antón de Olmet no repitió como diputado, nadie la retomó en el siguiente período de sesiones ${ }^{28}$.

Unos años después, en 1917, aunque ya no es diputado vuelve a aparecer el nombre de Luis Antón de Olmet en otra solicitud custodiada por el archivo de la Cámara, en la que se dirige al presidente, don Miguel Villanueva ${ }^{29}$. Se trata en esta ocasión de un documento mecanografiado con el membrete de director de $\mathrm{El} \mathrm{Par}$ lamentario y en él solicita a la Presidencia que ordene lo que sea conveniente para que la biblioteca del Congreso adquiera algunos ejemplares del Cancionero de mi tierra que recientemente ha publicado su hermana, la también escritora Casilda Antón $^{30}$. Este asunto se discute en la Sesión de la Comisión de Gobierno Interior que se celebra el 21 de abril de 1917, tal y como figura en una anotación manuscrita del Secretario y como viene también a corroborar el acta de dicha sesión.

\section{OLMET ESCRITOR}

En la obra Las Cortes Españolas: las de 1914 se dice que con apenas 30 años, «y sin perjuicio del artículo diario» (Sánchez y de la Redondela 1914,

${ }^{27}$ ACD, Serie General, legajo 421, núm. 103, «Proposición de ley concediendo una pensión de 7.500 pesetas anuales al poeta mejicano Amado Nervo».

${ }^{28}$ La bibliografía que sobre Amado Nervo ha abordado esta cuestión ha ofrecido hasta la fecha, sin embargo, otra explicación. Según indica José Simón Díaz la proposición de Antón del Olmet prosperó, si bien Amado Nervo fue quien, a través de una carta, renunció a esta pensión. Simón Díaz recoge un párrafo de esta carta citada a través de Manuel Durán y Lucio Mendieta Núñez y María Elena de Anda (Simón Díaz 1993, 176). No es esta una información precisa, pues a la luz de los diarios de sesiones y el expediente del Archivo del Congreso citados, el iter parlamentario de la cuestión fue otro.

29 ACD, Gobierno Interior, legajo 91, núm. 22: Solicitud de Luis Antón de Olmet para que se adquieran ejemplares del Cancionero de mi tierra.

${ }^{30}$ La de Antón del Olmet era, sin duda, una familia de escritores. Además de él, como ya se ha indicado, también sus hermanos Fernando y Casilda se dedicaban a las letras. 
587-588), pues Luis Antón del Olmet es escritor y periodista, y combina ambas facetas de forma constante, es un prolífico escritor. En concreto, se citan ya las siguientes obras:

El libro de la vida bohemia.- Lo que han visto mis ojos.- El encanto de tus manos.- Hieles.- El veneno de la víbora.- Mi risa.- Corazón de leona.- Su señoría.Como la luna, blanca.- Nuestro abrazo a Portugal.- Espejo de los humildes.- El hidalgo D. Tirso de Guimaraes.- Tierra de promisión.- Política de fandango y gobierno de castañuelas (dos tomos).- $\mathrm{Al}$ amor de mi pañosa.

En colaboración con Arturo G. Carraffa: Galdós.- Echegaray.- Maura.- Canalejas.- Moret.- Alfonso XIII (dos tomos).- Menéndez Pelayo.- Cajal.- Benlliure.Marina.- La emperatriz Eugenia.

Rubén López Conde, en la ya citada reedición de Historias de asesinos, tahúres, daifas, borrachos, neuróticas y poetas, ofrece un apéndice bibliográfico completo de la obra de Antón del Olmet por años (Antón del Olmet 2012, [29-34]). Conviene de nuevo recordar que esta extensísima producción literaria es alumbrada en paralelo a la intensa actividad periodística del autor, que no deja de publicar en prensa como redactor, corresponsal y director de diversos órganos.

Existe una división fundamental a la hora de aproximarse a la prolija bibliografía de Antón del Olmet, y es que se presenta una cesura clara entre su obra de creación, en la que aborda géneros diversos (novela, relato corto, poesía y teatro) y el resto de su obra, donde no sólo se encuentran las biografías que noveló, sino también otra serie de obras dedicadas a revivir su trayectoria política, a modo, en parte, de memorias o recopilaciones de artículos literarios.

Las biografías que escribe se agrupan en una serie que lleva por nombre «Los grandes españoles»; una serie biográfica que gozó de un éxito considerable y en la que trabajó con dos colaboradores: José de Torres Bernal y Arturo García Carraffa. Según justifica Juan Carlos Ara Torralba en la presentación de la edición de la biografía de Joaquín Costa hecha por la Institución Fernando el Católico (Ara Torralba 2010), la biografía moderna, y los trabajos biográficos de Olmet en concurso con sus colaboradores pueden considerarse así, logra abrirse hueco en el mercado bibliográfico español de principios del siglo pasado junto a las colecciones de quiosco y lo que el autor denomina «la literatura política del día» (Ara Torralba 2010, 6). Hay precedentes de series similares a la que crea Olmet, tales como «Personajes ilustres», impulsadas por la editorial de La España Moderna, «Celebridades españolas y sudamericanas», de Mundo Latino, o "Vidas de grandes hombres», de Seix Barral y Hermanos. Gracias, en buena parte, a ellas, en la segunda década del siglo XX el género biográfico está ya asentado y goza de un público objetivo, por lo que esta empresa de Olmet, que se imprimió unas veces en las prensas de la Imprenta de Alrededor del Mundo, y otras en las de la Imprenta de Juan Pueyo, es probable que gozase de celebridad e, incluso, éxito, como afirma Ara Torralba $(2010,5)$. 
Las líneas maestras de la serie se encuentran recogidas en el prólogo del primer volumen de la serie, el dedicado a Galdós:

Nos proponemos, al comenzar esta Biblioteca, dejar en libros compendiosos las vidas complejas, amenísimas, curiosas, ejemplares, de aquellos españoles insignes que tuvimos la fortuna de conocer y admirar en nuestra juventud, y que si hoy ya son célebres, mañana serán inmortales (Antón del Olmet y García Carraffa 1912, 5-6).

Así, esta serie biográfica se dedica a personajes contemporáneos, cuyos retratos se dibujan a partir en muchos casos de informaciones directas, entrevistas en el caso de Galdós o, en el de Joaquín Costa, de las memorias del político que son transcritas por Tomás Costa. Los personajes escogidos tienen diversas ocupaciones; son políticos, científicos, artistas, escritores, pero todos ellos gozan de celebridad, motivo este por el que el éxito comercial de estos libros estaba asegurado.

Benito Pérez Galdós inaugura, pues, esta biblioteca de hombres ilustres, pero por ella desfilarán los políticos Joaquín Costa (Antón del Olmet, 1920) ${ }^{31}$, Romanones (Olmet y Torres, 1922), Moret (Antón del Olmet y García Carraffa, 1913a) y Canalejas (Antón del Olmet y García Carraffa, 1916a); los escritores, además del mencionado Galdós, Echegaray (Antón del Olmet y García Carraffa, 1912a) ${ }^{32}$, Palacio Valdés (Antón del Olmet y Torres, 1919) ${ }^{33}$ y Menéndez Pelayo (Antón del Olmet y García Carraffa, 1913b); la actriz María Guerrero (Antón del Olmet y Torres, 1920); el general Marina (Antón del Olmet y García Carraffa 1916b); el científico Ramón y Cajal (Antón del Olmet 1918); y el rey Alfonso XIII (Antón del Olmet y García Carraffa 1913-1914). Son biografías interesadas, hechas a partir de entrevistas y el relato de los biografiados, que no esconden su necesidad de resultar atractivas para el público y para lo que se recurre a diversas argucias, pero constituyen también un testimonio de una época.

Antes de ellos escribió, fuera de esta colección, de Emilio Ortuño y Eloy Bullón, ya que son «el futuro de la política española»y «la esperanza del partido monárquico, en el que yo lucho también» (Antón del Olmet 1915b, 5-6).

31 Sobre esta obra vid. Ara Torralba 2010.

32 El ejemplar que de la biografía de Echegaray se conserva en la Biblioteca del Congreso de los Diputados tiene una dedicatoria del biografiado en la que indica «Para el libro que editan mis amigos D. Luis Antón del Olmet y D. Luis García Carraffa», y se firma en Madrid el 12 de junio de 1912. Esta es una de las biografías que se confecciona a través, entre otras cosas, de diversas entrevistas con el personaje del que escriben. Esto pudiera hacer pensar que sirvió a Olmet para establecer relaciones con importantes personajes de la vida pública y política.

${ }_{33}$ Palacio Valdés merece esta obra, en palabra de los autores, por ser «con Galdós, el mantenedor de la novela española después de Alarcón y antes de Blasco Ibáñez» (Antón del Olmet y García Carraffa 1912b, 11). 
Pareciera, pues, que en su cabeza estaba trazado el plan de dedicarse a biografiar a los grandes personajes de la vida política nacional, antes incluso de comenzar con esta serie editorial. Ya en el prólogo de su obra Al correr de la política: 1914 explica así su propósito:

Me propongo ir escribiendo sucesivamente unos anales de la política española. Eso ya lo hace don Fernando Soldevilla. Bueno será que otro escritor comparta la tarea, la tarea dificultosa, penosa, de trazar estos perfiles y estos apuntes, algún día convenientes para quien acometa la obra de escribir la historia contemporánea, y siempre útiles, pues refrescan la memoria de acontecimientos pasados, y sirven de enseñanza y ejemplo.

[...] Sin otra explicación voy, pues, á mi tema. Es decir, con una última advertencia. $\mathrm{Y}$ es que, en estos libros, ganoso de prestarle á mis lectores queridos un servicio modesto de información y de curiosidad, casi decido abstenerme de todo comentario para que la vida pase real, sincera, inmaculada, ante nuestros ojos; y que cuando sea preciso el comentario lo haré con toda serenidad, lejos ó cerca del partido al que estoy afiliado, sin otros compromisos que aquellos que son eternos que todo escritor celoso de su nombre contrae con la opinión pública: honrada intención y juicio desapasionado (Antón del Olmet 1915a, 5-6) 34 $^{34}$

En la producción literaria de Olmet ocupan también un papel relevante sus obras dramáticas. El Diccionario Akal de Teatro (Gómez García 2007, 47) cita varias de sus obras teatrales y dice de su producción era «de intenciones sociales», si bien a su título El sembrador lo describe como «comedia política». Cita, además de esta, El señorito Ladislao, que escribe en concurso con Vidal y Planas, No es lo mismo, novela dialogada en tres jornadas, La casa de los espantos, de 1921, La canción del juglar, ;Mala madre! y El pleito.

\section{UNA MUERTE PROPIA DE LA CRÓNICA DE SUCESOS}

Las circunstancias que rodearon la muerte de Luis Antón del Olmet son bien conocidas gracias a la prensa de la época. Fue Alfonso Vidal y Planas (1891-1965) quien disparó la pistola que le dio muerte en el Teatro Eslava el mediodía del 1 de marzo de 1923. Sin embargo, lo que no está tan claro es qué motivos llevaron a Vidal y Planas a su asesinato. La muerte de Luis Antón del Olmet fue, como toda su vida, excesiva, contradictoria, llena de claros y oscuros, sin buenos tan buenos ni malos tan terribles, para la que hubo móviles, justificaciones y explicaciones de todo tipo; también numerosas incongruencias

\footnotetext{
${ }^{34}$ A pesar de lo que pudiera hacer sospechar el título de esta obra y de algunos capítulos de carácter más general, el libro se dedica casi por completo a la figura de Antonio Maura. También el retrato de aquel que inauguraba la edición ofrece una pista concluyente sobre la centralidad de su figura en el relato que sobre el año 1914 en la política española ofrece su autor.
} 
y versiones divergentes, ya desde el mismo momento del acontecimiento y el traslado del escritor, muerto para algunos y agonizante para otros, a la casa de socorro donde permaneció su cadáver.

Rubén López Conde de nuevo ofrece otra recopilación de gran interés: las menciones publicadas en la prensa contemporánea relativas a este suceso organizadas por cabeceras. En concreto, ABC, El Heraldo de Madrid, La Voz: Diario Independiente de la Noche, La Libertad, La Época, El Sol, El Liberal, La Acción. Diario de la Noche, El Imparcial, La Correspondencia de España y El Nuevo Mundo cubren el acontecimiento (Antón del Olmet 2012, [34-37]). Asimismo Alberto Sánchez Álvarez-Insúa y Javier Barreiro se han ocupado también de estudiar este crimen, el primero en el volumen colectivo editado por Antonio Cruz Casado (Sánchez Álvarez-Insúa 2005) y el segundo en Cruces de Bohemia (Barreiro 2001).

Alfonso Vidal y Planas es un personaje complejo que también ha sido retratado por diversos autores. Allen W. Phillips lo ubica en lo que él denomina «segunda generación de bohemios profesionales» (Phillips 1988, 411), y aporta también algunos datos de utilidad para trazar su perfil: «Hacia 1920 era una figura típica de la bohemia literaria: exseminarista, vagabundo, militar, presidiario y golfo auténtico [...]. Vidal y Planas era una persona rebelde y agresiva, de carácter difícil [...]. Sus temas: el presidio, la locura, el prostíbulo y el hampa» (Phillips 1988, 411-412).

La relación entre ambos, asesinado y asesino, había sido larga, complicada, y terminó de modo dramático. La prensa atribuye a los celos profesionales, pero también a los celos sentimentales este trágico desenlace. Cansinos Assens relata en sus memorias las malas artes de Antón del Olmet en su periódico El Parlamentario, donde tiene no pocas trifulcas y desde el que su director practica el chantaje, causando contratiempos diversos a sus redactores. Cansinos Assens cuenta que Vidal y Planas llevó varios días vendada la cabeza por un encontronazo que a cuenta de Olmet tuvo con el dueño de una casa de empeños, y esto, en lugar de despertar otros sentimientos en el jefe, tan solo servía para azuzar sus chanzas (Cansinos 1995, 2: 51-52).

El escritor sevillano describe al asesino, Vidal y Planas, con mucha más tolerancia que al asesinado en los retratos que hace de ambos años antes de que el asesinato se produzca. Tanto es así que llega a afirmar que a Vidal y Planas le ha dañado, y no solo físicamente, como se acaba de contar, trabajar para Antón del Olmet, sino que también esto «perjudicó su buen nombre y desvalorizó su pluma, una pluma vibrante, bella y a ratos genial» (Cansinos 1995, 2: 105).

Da noticia de la muerte de Olmet después, cuando va a visitar a Vidal y Planas a la prisión (Cansinos 1995, 3: 73-76). En estas páginas cuenta, sin confirmar realmente si los acontecimientos tuvieron o no esta causa, que ha sido idea del abogado defensor de Vidal relacionar el homicidio con un asunto de amores. Dice Cansinos «se trata de dar al homicidio un aire retrospectivo 
de venganza calderoniana de un marido ultrajado, por el supuesto asedio amoroso de que Antón del Olmet hacía objeto a su amiga, esta Elena que ahora justifica lo fatal de su nombre» (Cansinos 1995, 3: 73-76).

Olmet, resume Cansinos, no fue un hombre querido. Al narrar el paso de su asesino por el banquillo afirma:

Cosa digna de notarse y que prueba la clase de hombre que era el interfecto, es que ni su hermano, el marqués de Dos-Fuentes, ni su viuda han designado acusador privado... Valero Martín [abogado de Vidal y Planas], en su defensa, traza en términos duros la figura moral de Antón del Olmet, describe los vejámenes de que hacía objeto a su defendido y trata de dar al festo de éste el sentido de una vindicación calderoniana del honor, como si Elenita Manzanares, con la que se casó en la cárcel, hubiese sido ya entonces su esposa (Cansinos 1995, 3: 159-160).

Vidal y Planas no llega a cumplir toda la condena. Apenas tres años, de los doce a los que fue condenado, pasa en la prisión del Dueso, según Cansinos (1995, 3: 202-204) y Barreiro $(2007,91)^{35}$, cerrando así lo que tuvo que ver con su tormentosa relación con quien fuera su jefe en El Parlamentario. Luego, ya en libertad, siguió escribiendo, participó en la Guerra Civil como miliciano anarquista y, a su fin, partió al exilio y se dedicó a la docencia mientras continuaba escribiendo.

Olmet, por su parte, luego de alimentar con su deceso las truculentas crónicas de los periódicos e inspirar diversas novelas que trataban de narrar y explicar su muerte, entre ellas la que se vendía por treinta céntimos y que llevaba por título Porqué asesinó Vidal y Planas a Antón del Olmet? (La novela del momento), cayó en el olvido y su obra se sumió en el silencio; y esa, la esterilidad de un libro o una obra es, como pone Enrique Pérez Escrich, autor de El frac azul y uno de los precursores de la bohemia en España, en boca de uno de sus personajes, «el mayor castigo que puede recibir aquel que lo ha escrito» ${ }^{36}$.

\section{BiBLIOGRAFÍA CitADA}

Antón del Olmet, Luis. 1909. El libro de la vida bohemia. Madrid: Establecimiento Tipográfico de Juan Ratés.

Antón del Olmet, Luis. 1911. Su señoría. Libro parlamentario. Madrid: Imprenta de Alrededor del Mundo.

\footnotetext{
35 Javier Barreiro señala, además, que Artemio Precioso no solo veló por su bienestar durante el tiempo que estuvo en prisión, sino que también tuvo mucho que ver en la campaña que a favor del indulto de Vidal y Planas se puso en marcha (Barreiro 2007, 90-92).

${ }^{36}$ Este pasaje es citado por Phillips al analizar una de las más tempranas manifestaciones de la bohemia en España que es El frac azul (1864), de la que dice que «inicia la modalidad en el país» (Phillips 1988, 394).
} 
Antón del Olmet, Luis. 1914. Política de fandango y gobierno de castañuelas. Madrid: Imprenta de Juan Pueyo.

Antón del Olmet, Luis. 1915a. Al correr de la política: 1914. Madrid: Imprenta de Juan Pueyo.

Antón del Olmet, Luis. 1915b. Pedagogía nacional: la obra de Eloy Bullón. Madrid: Imprenta Cervantina.

Antón del Olmet, Luis. 1916. Marruecos (de Melilla a Tánger). Madrid: Imprenta de Juan Pueyo.

Antón del Olmet, Luis. 1917. Los idóneos: la horrenda política. Recuerdo de un exsecretario político, intimidades del partido llamado conservador. Madrid: Imprenta de Juan Pueyo.

Antón del Olmet, Luis. 1918. Cajal. Historia intima y resumen científico del español más ilustre de su época. Madrid: Imprenta de Juan Pueyo.

Antón del Olmet, Luis. 1919. Maura es obra mía (España en pie). Madrid: Imprenta de Juan Pueyo.

Antón del Olmet, Luis. 1921. Gobernación, Sánchez Mínguez: novela. Madrid: Renacimiento.

Antón del Olmet, Luis. 2012. Historia de asesinos, tahúres, daifas, borrachos, neuróticas y poetas. Editado por Rubén López Conde. [Almería]: Ginger Ape Books\&Films.

Antón del Olmet, Luis. 2013. La vampira de la calle Poniente: crónica de un suceso. [Jaén]: Ginger Ape Books\&Films.

Antón del Olmet, Luis y Arturo García Carraffa. 1912a. Galdós. El insigne literato cuenta su vida, enumera sus triunfos, recorre toda su obra literaria, expresa sus ideas políticas y religiosas, se asoma al público contando sus intimidades, hace una sintesis total de su existencia. Madrid: Imprenta de Alrededor del Mundo.

Antón del Olmet, Luis y Arturo García Carraffa. 1912b. Echegaray, el insigne polígrafo cuenta su vida luminosa, llena de aventuras geniales y de hazañas fuertes, ofreciendo al público el ejemplo de su existir glorioso. Madrid, Imprenta de Alrededor del Mundo.

Antón del Olmet, Luis y Arturo García Carraffa. 1913-1914. Alfonso XIII. 2 vols. Madrid: Imprenta de Alrededor del Mundo.

Antón del Olmet, Luis y Arturo García Carraffa. 1913a. Moret. Páginas que guardan el sutil perfume de una vida que fue todo elegancia. Madrid: Imprenta de Juan Pueyo.

Antón del Olmet, Luis y Arturo García Carraffa. 1913b. Menéndez Pelayo, ex voto de amor $y$ de respeto que rinden ante la imagen de un coloso español dos patriotas. Madrid: Imprenta de Juan Pueyo.

Antón del Olmet, Luis y Arturo García Carraffa. 1916a. Canalejas: libro en cuyas páginas resplandece la insigne figura del muerto inolvidable. Madrid: Imprenta Sáez Hermanos y Cía.

Antón del Olmet, Luis y Arturo García Carraffa. 1916b. El general Marina, páginas que reflejan la vida heróica, austera y gloriosa de un soldado que ganó tierras para España. Madrid: [Sociedad General Española de Librería y Publicaciones].

Antón del Olmet, Luis y Arturo García Carraffa. 1920. Costa. Libro que recoge el trágico lamento de una raza en la figura del más egregio patriota. [Madrid]: [Imprenta de Juan Pueyo].

Antón del Olmet, Luis y José de Torres Bernal. 1919. Palacio Valdés. Análisis de ese alma blanca y angélica y de ese astro sano y optimista que se llama D. Armando Palacio y Valdés. Madrid: Imprenta de Juan Pueyo.

Antón del Olmet, Luis y José de Torres Bernal. 1920. María Guerrero. En esta obra se halla resumida la vida llena de arte y encanto, maravillosa vida ejemplar, de la egregia comediante. Madrid: Renacimiento. 
Antón del Olmet, Luis y José de Torres Bernal. 1922. Romanones. Libro que resume la vida interesante, racial, de este sagaz, demócrata e insigne político español. Madrid: Imprenta de Juan Pueyo.

Ara Torralba, Juan Carlos. 2010. «El Costa de Luis Antón del Olmet o la interesada biografía al uso periodístico de un ex datista». En Costa, edición electrónica sobre el original de 1917. Estudio introductorio de Juan Carlos Ara Torralba, Luis Antón del Olmet. $<$ http://ifc.dpz.es/publicaciones/ver/id/3027> [Consulta: 20/01/2017].

Barreiro, Javier. 2001. Cruces de bohemia (Vidal y Planas, Noel, Retana, Gálvez, Dicenta y Barrantes). Zaragoza: Unaluna Ediciones.

Barreiro, Javier. 2007. «Los bestsellers de la bohemia española». Boletín Hispano-Helvético 10: $81-100$.

Cansinos Assens, Rafael. 1995. Novela de un literato: hombres, ideas, efemérides, anécdotas... 3 vol. Madrid: Alianza Editorial.

Gálvez, Pedro Luis de. 1926. «A Luis Antón del Olmet no lo mató Vidal y Planas». El Escándalo. Barcelona, 20 de mayo.

Gómez García, Manuel. 2007. «Antón del Olmet, Luis». En Diccionario Akal de Teatro. Madrid: Akal.

Hernández Cano, Eduardo. 2010. «Luis Antón del Olmet». En Diccionario biográfico español, Amador de los Ríos y Serrano-Arcas Sánchez, 476-478. Vol. IV. Madrid: Real Academia de la Historia.

Martorell Linares, Miguel Ángel. 1997. «La crisis parlamentaria de 1913-1917. La quiebra del sistema de relaciones parlamentarias de la Restauración». Revista de Estudios Politicos 96: 13 7-161.

Martorell Linares, Miguel Ángel. 2010. «José Sánchez Guerra: conservador a fuer de liberal». Hispania LXX, 234: 75-100. https://doi.org/10.3989/hispania.2010.v70.i234.158

Phillips, Allen W. 1988. "Apuntes para el estudio de la bohemia en algunas novelas modernas (1880-1930)». Anales de Literatura Española de la Universidad de Alicante 6: 391-442. https://doi.org/10.14198/ALEUA.1988.6.18

Prada, Juan Manuel de. 2008. Las máscaras del héroe. Madrid: Seix Barral.

Ramos Rovi, M. ${ }^{a}$ José. 2013. Diccionario biográfico de parlamentarios andaluces (18761923). Sevilla: Universidad de Sevilla.

Sánchez Álvarez-Insúa, Alberto. 2005. «Madrid, 3 de la tarde del 2 de marzo de 1923: Alfonso Vidal y Planas mata de un disparo a Luis Antón del Olmet en el saloncillo del Teatro Eslava». En Bohemios, raros y olvidados. Actas del Congreso Internacional, celebrado en Lucena (Córdoba), del 4 al 7 de Noviembre de 2004, ed. Antonio Cruz Casado, 701-729. Córdoba: Diputación de Córdoba - Ediciones y Publicaciones y Ayuntamiento de Lucena.

Sánchez de los Santos, Modesto y Simón De la Redondela. 1914. Las Cortes Españolas: las de 1914. Madrid: Establecimiento Tipográfico de A. Marzo.

Simón Díaz, José. 1993. «Amado Nervo y Madrid». Anales de literatura hispanoamericana 22: $165-185$.

Urbina, Rafael. 1919. «El teatro, los libros y el arte en España». Cosmópolis VIII: 678-679.

Fecha de recepción: 16 de marzo de 2017.

Fecha de aceptación: 23 de agosto de 2017. 